(3)

Volume 24, 2021

\title{
UNDERSTANDING OF THE QUALITY OF COMPUTER- MEDIATED COMMUNICATION TECHNOLOGY IN THE CONTEXT OF BUSINESS PLANNING
}

\begin{tabular}{ll}
\hline Junghyun Nam & $\begin{array}{l}\text { University of North Georgia, } \\
\text { Dahlonega, Georgia, USA }\end{array}$
\end{tabular}

\section{ABSTRACT}

Aim/Purpose

This study seeks to uncover the perceived quality factors of computer-mediated communication in business planning in which communication among teammates is crucial for collaboration.

Background

Computer-mediated communication has made communicating with teammates easier and more affordable than ever. What motivates people to use a particular CMC technology during business planning is a major concern in this research.

Methodology

This study seeks to address the issues by applying the concept of Information Product Quality (IPQ). Based on 21 factors derived from an extensive literature review on Information Product Quality (IPQ), an experimental study was conducted to identify the factors that are perceived as most relevant.

Contribution

The findings in this study will help developers find a more customer-oriented approach to developing CMC technology design, specifically useful in collaborative work, such as business planning.

Findings

This study extracted the three specific quality factors to use CMC technology in business planning: informational, physical, and service.

Keywords

computer-mediated communication, business planning, instant messaging, information product quality, information quality

\section{INTRODUCTION}

Computer-mediated Communication (CMC) is defined as any human communication utilizing the use of electronic devices (McQuail, 2005). CMC technologies include email, text messaging, instant messaging (IM), Social Network Services (SNS), chatting services, etc. (Ellison et al., 2007). CMC is

Accepting Editor Eli Cohen | Received: August 28, 2021 | Revised: October 2, October 3, 2021 |

Accepted: October 5, 2021.

Cite as: Nam, J. (2021). Understanding of the quality of computer-mediated communication technology in the context of business planning. Informing Science: The International Journal of an Emerging Transdiscipline, 24, 111-127. https://doi.org/10.28945/4872

(CC BY-NC 4.0) This article is licensed to you under a Creative Commons Attribution-NonCommercial 4.0 International License. When you copy and redistribute this paper in full or in part, you need to provide proper attribution to it to ensure that others can later locate this work (and to ensure that others do not accuse you of plagiarism). You may (and we encourage you to) adapt, remix, transform and build upon the material for any non-commercial purposes. This license does not permit you to use this material for commercial purposes. 
one of the commonly used Information Products nowadays. An Information Product is a highly interdependent package of information that can be digitized and can be transmitted, and distributed in digital form (Shapiro \& Varian, 1998). With the advent of the Internet and high-speed internet connection, $\mathrm{CMC}$ has been one of the most widely used communication tools and a keystone of computer-supported collaborative work. CMC technologies enable people to record/store information, reduce delays in communication, improve coordination of people remotely located, support reflection and composition of information, and improve user capabilities in information processing (Baltes et al., 2002).

Due to the necessity of using information products as a gateway for collecting data that could be exploited for marketing purposes, the design of the $\mathrm{CMC}$ has recently been more directed toward the needs of the businesses. For example, digital companies, using the huge amount of customers' online activity data, use predictive analytics to create new business values/opportunities. They consider consumer data as the most important data asset. Sometimes, they use the assets without the consent of customers. Recently, there has been a concern that Facebook has been collecting customers' call records and SMS data for years. However, little is known about the desires of users in the use of CMC, as well as what their main concerns in the use of CMC are. The major focus directed towards the businesses of the digital company now should be directed more towards the desires of the users. To create a new value for customers, understanding how users perceive the quality of CMC is important.

Effective communication in the workplace is key to the long-term success of an organization, and CMC plays an integral part in collaboration at the workplace. For business planning, CMC plays a crucial role in helping coworkers to communicate effectively. A collaborative team may be presented with various $\mathrm{CMC}$ technologies (email, phone, instant messaging, applications, etc.) for the support of distributed collaborative work. The purpose of this study is to investigate what quality factors users perceive important in using CMC in business collaboration. In this research, Nam (2014)'s information product quality model will be adopted as a theoretical framework. The framework will be used to find out which factors users perceive important in CMC use, especially in a business planning collaboration. The understanding of quality factors important in CMC use in business planning is applicable in other collaboration work as well. The right choice of $\mathrm{CMC}$ technology may facilitate or delay collaborative work. CMC plays a crucial role in any collaboration work these days. Therefore, the understanding of the quality of CMC in collaboration may result in better design of CMC technology.

The paper is organized in the following way: In the following section, the theoretical foundations of this research will be discussed, including a review of the features of CMC technologies and a brief introduction of the information product quality concept. In the methodology section, the research method, including instrument design and data collection, is discussed. The Data Analysis and Research Findings section will include data analysis, findings, and discussion on the findings to extend understanding to user's perception of CMC quality. Finally, I will summarize the research results and implications for researchers and practitioners and make a brief conclusion and directions for future research.

\section{LITERATURE REVIEW}

\section{COMPUTER-MEDIATED COMMUNICATION}

$\mathrm{CMC}$ technologies are becoming an important tool at the workplace. People use CMC for various reasons, for example, to reduce delays in communication, improve coordination, store/record information, to reflect and compose information, improve information processing, etc. (Baltes et al., 2002). CMC is defined as any human communication utilizing the use of electronic devices (McQuail, 2005). Therefore, technologies such as email, text messaging, instant messaging (IM), Social Network Services (SNS), chat rooms, and blogs can be considered as CMC technologies (Ellison et al., 2007; McQuail, 2005). Various software tools have been changing the way we communicate and 
collaborate at the workplace, ensuring that physical barriers are no longer problematic for communicating purposes. One innovative example is the Virtual Reality Conference, which combines 360 videos and VR technology to create a VR teleconference system that gets as close as possible to actually being located in the same place.

As more and more companies continue to find ways to embrace more innovative communication tools, the possibilities for new and innovative solutions will continue to grow. According to 20052016 American Community Survey (US Census Bureau) data, regular work-at-home, among the nonself-employed population, has grown by $140 \%$ since 2005 , nearly ten times faster than the rest of the workforce or the self-employed. Larger companies are most likely to offer telecommuting options to most of their employees. Fortune 1000 companies are entirely rearranging their space around the fact that employees are already mobile. Studies repeatedly show employees are not at their desks 50-60\% of the time. All kinds of telecommuting tools are on the rise. One hundred three percent increase from 2005-2016 alone (Global Workplace Analytics, 2018).

In this study, $\mathrm{CMC}$ use in business planning is the focus. People may consider using various types of CMC technologies, such as email, text messaging, instant messaging (IM), Social Network Services (SNS), chat rooms, blogs, etc. Media richness theory (Daft \& Lengel, 1986) classifies communication technology along a continuum of "Richness," Richness implies capabilities to carry visual social cues, provide rapid feedback, and convey personality. Therefore, each medium may show a different capability to communicate complex messages. Comparably, lean media are less effective for communicating complex issues than rich media. Some people may prefer to utilize the richer CMC technology for communication since it incorporates more cues to increase communication performance. Others may prefer to choose lean media for certain tasks, considering social influences and geographic distribution. For example, people may choose lean medium over rich medium to prevent embarrassment or to avoid upsetting others. Fulk et al. (1990) found that social influence (user's social work and social circle, peer pressure, culture difference, and previously developed context-specific mental schemas) has a strong influence on CMC media use.

Instant Messaging, like Skype, iMessage, Telegram, Facebook Messenger, WhatsApp, etc., is getting popular as it shows multimedia functions, such as text, voice, video transmission, with a capability to be aware of the online presence status of their communication partners. The most popular IM in South Korea is KakaoTalk. Among various IM applications, 95\% of the estimated 43 million smartphone users in South Korea mainly used KakaoTalk in 2017 (The Korea Herald, 2017). KakaoTalk users can share photos, links, videos as well as free video/audio calls, group chats, and messages. The app may automatically synchronize the user's contact list on their smartphones with the KakaoTalk contact list. Users can search for people by KakaoTalk ID without a phone. The app has a built-in browser, so users can open links and view websites while using the app. KakaoTalk has targeted countries in Southeast Asia as well, such as Malaysia, Indonesia, Philippines.

Email is mainly transmitting/receiving text and attachments. As an asynchronous CMC technology, it is not possible to check the online presence status of their partners. Social Networking Services (SNS) is a technology that enables users to share their interests, personal life, and stories with friends, acquaintances, and even with strangers. SNS allows users to upload text, pictures, audio, videos, news, and programs. Users can adjust privacy settings to select the audience before they share the content. SNS companies, such as Facebook, Twitter, Instagram, etc., are getting popular and driving a huge volume of traffic.

Researchers have examined the role of CMC technology in various organizational settings. Scheibe and Gupta (2017) found that computer-mediated socializing generates higher organizational creativity than low computer-mediated socializing when an organization has a rational culture. Rational culture is the organizational culture in which accomplishment/productivity/impact/profit is highly valued (Scheibe \& Gupta, 2017). Sirait and Zellatifanny (2020) investigated the patterns and the effectiveness of computer-mediated communication and 
collaboration among government employees during the Covid-19 pandemic. The results show that most employees have used instant messaging, online meeting applications, email, and document sharing tools to collaborate remotely. Tate et al. (2019) measured dimensions of employee engagement among telecommuting knowledge workers in the US using the five subscales of the Computer-mediated Communication (CMC) competence model (i.e., expressiveness, attentiveness, efficacy, knowledge, \& motivation). They found that the most significant predictor of engagement was attentiveness, followed by expressiveness and then motivation (Tate et al., 2019).

CMC allows individuals to interact and share ideas with each other regardless of their physical location, so it may play an important role in enhancing business planning outcomes. Even though literature shows that there are various CMC technologies available and popularly used, and each CMC technology has different capabilities, functions, and different levels of Richness, there has been little research work in examining quality factors of $\mathrm{CMC}$ technology that may be perceived as important for collaborative work.

\section{BUSINESS PLANNING}

Entrepreneurship courses have become one of the essential courses in many business schools. Honig (2004) examined the 2004 college catalogs of all of the top 100 universities in the United States for courses that specifically referred to Entrepreneurship in their course description. He found 78 of the top 100 universities offered such courses. Entrepreneurial education programs have a positive effect on the perceptions of the desirability and feasibility of starting a business (Peterman \& Kennedy, 2003). This process is driven by the expectation that the university can be an engine to stimulate local economic growth and social well-being, and university management seeks to expand the university funding base in accord with governmental policies and initiatives (R. Graham, 2014).

In entrepreneurship courses, students learn how to write a business plan. A business plan can be defined as a written document setting out a business's objectives and describing in detail, including business goals, an industry and competitor analysis, an examination of environmental trends/resources, the organizational and financial strategies, and detailed activities of marketing, operation, production, and management. As the course content includes case materials, simulations, and various "hands-on" approaches (Gorman et al., 1997), teaching how to write a business plan and monitoring of the production is identified as being the most important course feature of entrepreneurship courses (Hills, 1988). Business planning projects require a significant amount of collaborative effort among team members. Students typically work in groups to write a business plan. They present the business plan in the classroom to demonstrate the feasibility and quality of the plan. The instructors assess each team's achievement to see if each team effectively integrates course knowledge into the plan. To complete several weekly tasks to build a business planning, on-site or virtual meetings must take place. The management of the collaboration includes assembling, scheduling/coordinating meetings, monitoring of tasks completed, etc. If team members are distributed in different locations to collaborate towards a shared goal, CMC technologies play the role of a communication platform to accomplish a task. A proper communication tool decreases the risk of communication breakdowns and increases the chances to build a shared context. The business planning project follows similar procedures of real-life business planning, as students are expected to generate a business plan at the end of the semester for grading. Some limitations of this setting include lack of funding/resources/budget. For example, the subjects are students, so they prefer freeware to purchased software.

\section{CONCEPTUAL MODEL OF INFORMATION PRODUCT QUALITY (IPQ)}

An information product is an interdependent package of information that can be digitalized, transmitted, and distributed in digital form (Shapiro \& Varian, 1998). An information product has quality when it is beneficial to information product recipients. Crosby (1980) defines quality as "conform- 
ance to requirements." Deming defined quality from the customer's point of view as "satisfying customer's requirements" (Deming, 1986). The Information Product Quality concept will be adopted to measure the perceived quality of CMC. Any information product consists of three components: informational, physical, and service components (Alter, 2002). As a kind of Information Product, a $\mathrm{CMC}$ technology also has three components: informational, physical, and service.

Eppler's concepts of content quality and media quality are used to explain information and physical components, and SERVQUAL explains the service component of information product quality. Information Product Quality consists of three components: informational, physical, and service components. Informational components include comprehensiveness, accuracy, clarity, applicability, conciseness, consistency, correctness, and currency. Physical components include convenience, timeliness, traceability, interactivity, accessibility, security, maintainability, and speed. Service components include reliability, responsiveness, assurance, empathy, and tangibility. Nam $(2009,2014)$ tested the Information Product Quality model in the use of different types of information products, which is a general web portal. In this research, a total of 21 quality factors will be considered to measure CMC quality in business planning (Table 1).

Table 1. Conceptual Model of IPQ

\begin{tabular}{|c|c|}
\hline \multicolumn{2}{|c|}{ Information Product Quality (IPQ) } \\
\hline $\begin{array}{l}\text { Informational compo- } \\
\text { nents }\end{array}$ & $\begin{array}{l}\text { C1: Comprehensiveness } \\
\text { C2: Accuracy } \\
\text { C3: Clarity } \\
\text { C4: Applicability } \\
\text { C5: Conciseness } \\
\text { C6: Consistency } \\
\text { C7: Correctness } \\
\text { C8: Currency }\end{array}$ \\
\hline Physical components & $\begin{array}{l}\text { C9: Convenience } \\
\text { C10: Timeliness } \\
\text { C11: Traceability } \\
\text { C12: Interactivity } \\
\text { C13: Accessibility } \\
\text { C14: Security } \\
\text { C15: Maintainability } \\
\text { C16: Speed }\end{array}$ \\
\hline Service components & $\begin{array}{l}\text { C17: Reliability } \\
\text { C18: Responsiveness } \\
\text { C19: Assurance } \\
\text { C20: Empathy } \\
\text { C21: Tangibility }\end{array}$ \\
\hline
\end{tabular}

The quality of CMC also can be examined in three components. Physical components are the materials that hold data in a certain form or that allow data to flow. In this study, hardware or software that 
may hold, present, and deliver data in any form or that may allow data to flow is considered as a physical component. Information components are contents that users try to deliver. Service components are sets of actions that create values to users that do not include information nor physical components.

\section{RESEARCH QUESTION}

The most popular CMC technologies are Instant Messaging, email, and SNS (Ku et al., 2013). In this study, text messaging and telephone are also included. By adopting Nam (2009, 2014)'s information product quality model, this study investigates the following research question.

Research question: What quality factors are perceived as important in the use of CMC technologies in business planning?

In other words, given many factors that were discussed in the literature on information quality, which one would be pertinent to CMC use in business planning? In this study, the quality of CMC - as an information product - was examined from the perspective of end-users. Nam's Information Product quality model (2014) incorporated Eppler's (2003) information quality model and SERVQUAL. The definition of each quality factor in Nam's study was utilized in this study. A total of 21 quality dimensions are examined in this study. They are comprehensiveness, accuracy, clarity, applicability, conciseness, consistency, correctness, currency, convenience, timeliness, traceability, interactivity, accessibility, security, maintainability, speed, reliability, responsiveness, assurance, empathy, and tangibility. The list of dimensions appears in Table 2.

Table 2: Information Product Quality (IPQ) Attributes

\begin{tabular}{|l|l|l|}
$\begin{array}{l}\text { Quality } \\
\text { components }\end{array}$ & Quality attributes & Description \\
\hline $\begin{array}{l}\text { Informational } \\
\text { components }\end{array}$ & Comprehensiveness & $\begin{array}{l}\text { Is the scope of information adequate (not too much nor too } \\
\text { little) }\end{array}$ \\
\hline & Accuracy & $\begin{array}{l}\text { Is the information precise enough and close enough to real- } \\
\text { ity? }\end{array}$ \\
\hline & Applicability & $\begin{array}{l}\text { Is the information understandable or comprehensible to the } \\
\text { target group? }\end{array}$ \\
\hline Can the information be directly applied? Is it useful? \\
\hline
\end{tabular}




\begin{tabular}{|c|c|c|}
\hline $\begin{array}{l}\text { Quality } \\
\text { components }\end{array}$ & Quality attributes & Description \\
\hline \multirow[t]{8}{*}{$\begin{array}{l}\text { Physical com- } \\
\text { ponents }\end{array}$} & Convenience & $\begin{array}{l}\text { Does the information provision correspond to the user's } \\
\text { needs and habits? }\end{array}$ \\
\hline & Timeliness & $\begin{array}{l}\text { Is the information processed and delivered rapidly without } \\
\text { delays? }\end{array}$ \\
\hline & Traceability & $\begin{array}{l}\text { Is the background of the information visible? (author, date, } \\
\text { etc.) }\end{array}$ \\
\hline & Interactivity & $\begin{array}{l}\text { Can the information process be adapted by the information } \\
\text { consumer? }\end{array}$ \\
\hline & Accessibility & $\begin{array}{l}\text { Is there a continuous and unobstructed way to get to the in- } \\
\text { formation? }\end{array}$ \\
\hline & Security & $\begin{array}{l}\text { Is the information protected against loss or unauthorized } \\
\text { access? }\end{array}$ \\
\hline & Maintainability & $\begin{array}{l}\text { Can all of the information be organized and updated on an } \\
\text { ongoing basis? }\end{array}$ \\
\hline & Speed & Can the infrastructure match the user's working pace? \\
\hline \multirow{5}{*}{$\begin{array}{l}\text { Service com- } \\
\text { ponents }\end{array}$} & Reliability & Is the service able to perform its functionality accurately? \\
\hline & Responsiveness & $\begin{array}{l}\text { Is the service willing to help and provide its functionality in } \\
\text { an immediate form to the users? }\end{array}$ \\
\hline & Assurances & Is the service able to convey trust and confidence? \\
\hline & Empathy & $\begin{array}{l}\text { Is the service able to provide caring and individual atten- } \\
\text { tion? }\end{array}$ \\
\hline & Tangibility: & $\begin{array}{l}\text { Does the service contain all the software and hardware in- } \\
\text { frastructures needed according to its functionality? }\end{array}$ \\
\hline
\end{tabular}

\section{SUBJECTS AND PROCEDURE}

Entrepreneurship is one of the mandatory courses for an undergraduate student enrolled in Ulsan National Institute of Science and Technology, South Korea. In this study, data were collected from undergraduate students who are taking the mandatory entrepreneurship course at the UNIST. Partici- 
pation in this study was voluntary, and subjects were rewarded with extra course credits for their survey participation. The school (Ulsan National Institute of Science and Technology) required approval by a Human Subjects College, and IRB approved this study with EXEMPT from ongoing review.

The participants evaluated the perceived quality of CMC and the actual choice of CMC. A self-administered survey was done right after taking the "Entrepreneurship and innovation" course at the end of the semester. Subjects were asked the choice of CMC used the most in business planning projects. Subjects also evaluated the quality of the CMC, which they chose for their business planning collaboration. The scale in the Nam (2014)'s study was used with suitable modifications in a business planning project context to measure the perceived quality of CMC. To evaluate the quality of the

CMC, the questionnaire also asked participants to rate the extent to which they agree on a sevenpoint scale (anchored by 1: extremely unlikely, and 7: extremely likely).

\section{DATA ANALYSIS AND RESEARCH FINDINGS}

\section{DEMOGRAPHICS}

Two hundred eighteen undergraduate students—162 males (74\%) and 56 females $(26 \%)$ —enrolled in MGT102 Entrepreneurship courses at the Ulsan National Institute of Science and Technology during either the Spring or Fall semester in 2018-2019 participated in the survey. The average age among participants was 23.1 years old, with the youngest being 19 and the oldest being 28 years of age. The age of the majority of participants (91\%) ranged between 20 to 25 years old.

$94 \%$ of the subjects had their own laptop, and $29.4 \%$ of the participants had their own Tablet PC. all participants possessed their own smartphone. As a favorite mobile device in business meetings, 39\% of participants indicated laptop, $12.4 \%$ picked the mobile phone, and $33.5 \%$ participants chose both laptop and mobile phone at the same time. Most of the participants (about 90\%) have less than seven years of experience in mobile device use. The average year of mobile device use is 4.3 years, with a standard deviation of 7.2 years.

\section{EXPLORATORY FACTOR ANALYSIS}

To test and find the significant quality factors in CMC use, Exploratory Factor Analysis (EFA), using SPSS, was conducted with maximum likelihood extraction with iterations. Varimax rotation was specified to identify variables that might indicate potential constructs. Prior to performing the analysis, the accuracy of data entry, missing values, normality, and outliers was checked. This study conducted Exploratory Factor Analysis (EFA) in examining the validity of the instrument. EFA is usually conducted to identify and organize a large number of items of the questionnaire into the constructs under one specific variable (Chua, 2014).

Construct validity is the extent to which an empirical measure effectively tests the real meaning of concepts under consideration (Babbie, 1990). If the Kaiser-Meyer-Olkin (KMO) is greater than 0.6 and the Barletett's Test of Sphericity (BTS) is significant at $\alpha<.05$, then it is believed that the sampling is adequate to proceed for factor analysis (Hair et al., 2010; Tabachnick \& Fidell, 2007).

Four factors with eigenvalues over one were obtained. The four factors explained 58.72 percent of the variance. The reliability estimation for each quality factor is $.830, .820, .812$, and .630 . As Cronbach alpha values of 0.7 or higher indicate acceptable internal consistency, the fourth factor (Cronbach value is below 0.7) is dropped. The other three factors are named Physical, Information, and Service. The three factors explained 53.82 of the total variance. All of the values are statistically significant $(\mathrm{p}<.05)$. Each of Cronbach's alpha data analyzed is summarized in Table 3 . Table 3 displays the rotated loading for these factors. Data supports the original structure of the research 
model. KMO was 0.916 , it is greater than 0.6 , and BTS is significant at $\alpha=.000$, so it ensures the sampling adequacy for factor analysis.

\section{Table 3: Factor Loading Results}

\begin{tabular}{|c|c|}
\hline Factors & Attributes \\
\hline $\begin{array}{l}\text { Factor1:Physical } \\
(\text { Cronbach's alpha }=.830)\end{array}$ & $\begin{array}{l}\text { C16: Speed }(.719) \\
\text { C13: Accessibility }(.717) \\
\text { C10: Timeliness }(.701) \\
\text { C9: Convenience }(.854) \\
\text { C12: Interactivity }(.840) \\
\text { C19: Assurance }(.586)\end{array}$ \\
\hline $\begin{array}{l}\text { Factor2:Information } \\
(\text { Cronbach's alpha }=.820)\end{array}$ & $\begin{array}{l}\text { C5: Conciseness }(.724) \\
\text { C1:Comprehensiveness (.709) } \\
\text { C3: Clarity (686) } \\
\text { C2: Accuracy }(.656) \\
\text { C6: Consistency }(.502)\end{array}$ \\
\hline $\begin{array}{l}\text { Factor3:Service } \\
(\text { Cronbach's alpha }=.812)\end{array}$ & $\begin{array}{l}\text { C17: Reliability }(.759) \\
\text { C20: Responsiveness }(.743) \\
\text { C18: Assurance }(.592) \\
\text { C21: Tangibility }(.542)\end{array}$ \\
\hline
\end{tabular}

\section{CONFIRMATORY FACTOR ANALYSIS (CFA)}

The three factors were confirmed through a measurement model in AMOS 26 graphics. This model was expected to provide factor validity in this study. The AMOS 26 Maximum Likelihood solution algorithm was used to estimate model parameters. $\chi 2(87)$ of the model was $181.655(\mathrm{p}=.000)$. In addition, TLI $=.898$ (appropriate), $\mathrm{CFI}=.926$ (appropriate), the Root Mean Square Error of Approximation $($ RMSEA $)=0.071$ (good), 90 Percent Confidence Interval for RMSEA $=(0.056 ; 0.085)$, and PValue for Test of Close Fit (RMSEA < 0.05) $=0.000$. AMOS 26 uses Maximum Likelihood for the analysis of missing data. Chi-square value $(181.655) / \mathrm{df}(87)<5$, so this model is appropriate.

When the standardized factor loading of each item is higher than statistically significant levels, then good convergent validity exists (Dunn et al., 1994; Anderson \& Gerbing, 1988). In Figure 1, each variable exhibits significant loadings which support convergent validity. 


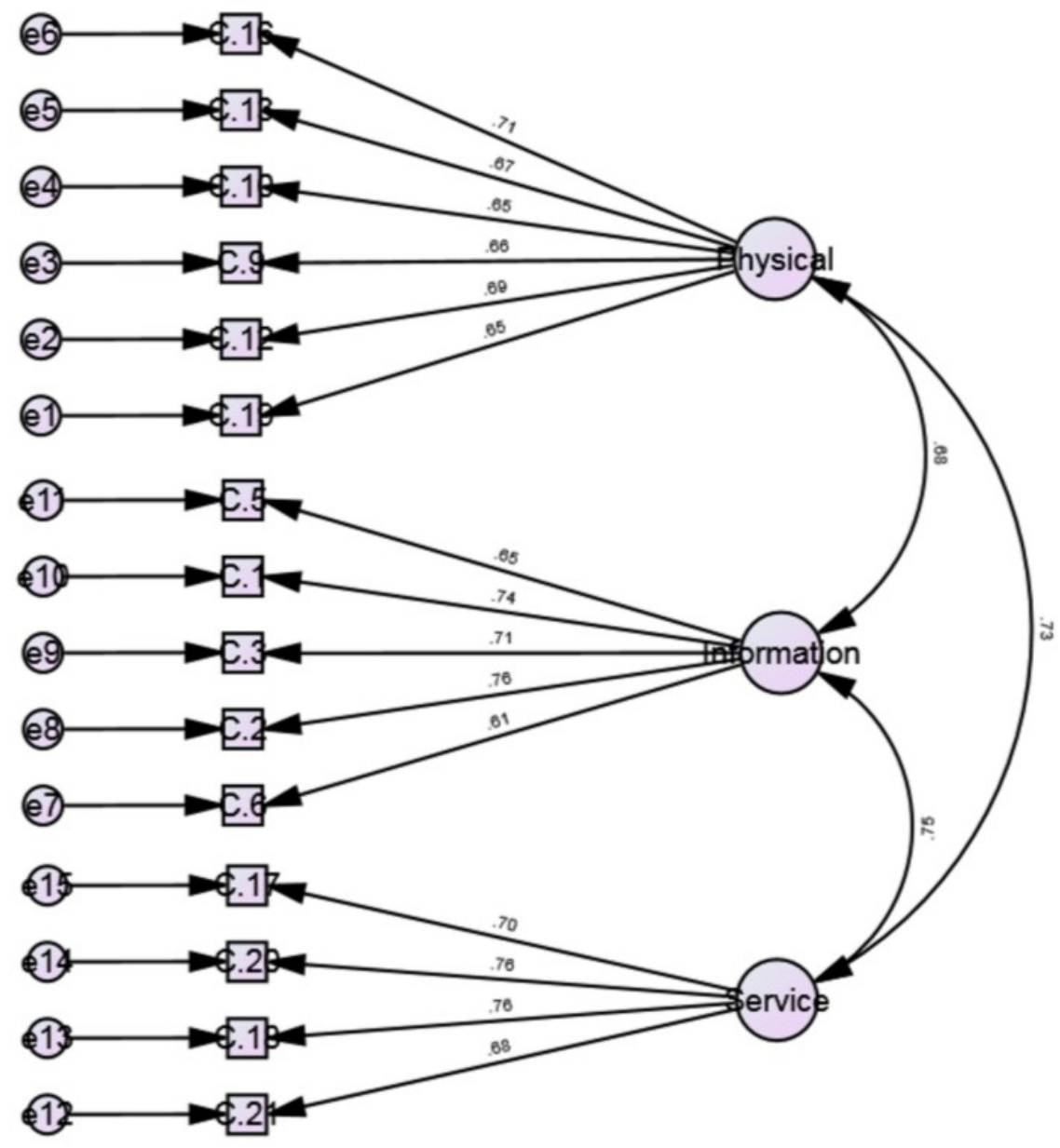

Figure 1: Standardized Factor Estimates

For discriminant validity, the estimated correlation parameter $\Phi$ ij between one pair of components was constrained to 1.0 , and a $\chi 2$ difference test was conducted on the values obtained from the constrained model and the unconstrained model. A chi-square difference test was conducted for each possible pair of the three factors at any given time (Anderson \& Gerbing, 1988). The unconstrained model shows a significantly lower value of $\chi^{2}\left(\left(\chi^{2}(1)=10.83, \mathrm{p}<.001\right)\right)$ than all the constrained models (see Table 4). Therefore, the factors possess discriminant validity.

Table 4: CMT Quality Factors

\begin{tabular}{|l|l|l|l|l|l|}
\hline $\begin{array}{l}\text { Factors con- } \\
\text { strained to unity }\end{array}$ & $\mathbf{X}^{\wedge} \mathbf{2}$ & $\mathbf{d f}$ & $\mathbf{p}$ & $\Delta \mathbf{X}^{\wedge} \mathbf{2}$ & $\Delta \mathbf{d f}$ \\
\hline unconstrained & 181.7 & 87 & 0.000 & & \\
\hline 12 & 217.1 & 88 & 0.000 & 35.4 & 1 \\
\hline 23 & 204.4 & 88 & 0.000 & 22.7 & 1 \\
\hline 13 & 202.2 & 88 & 0.000 & 20.5 & 1 \\
\hline
\end{tabular}




\section{RESULTS \& DISCUSSION}

As a major CMC technology used in business planning collaboration, Instant Messaging was chosen by the participants $(82.6 \%)$, with email $(15.1 \%)$ and mobile phone $(2.3 \%)$ ranked second and third, respectively. IM is a type of online service in which users can create a private chat room with other people to communicate in real-time. (Beal, 2019). IM is getting more popular at workplaces. IM is used to improve workflow, quality of workday, productivity, and interoffice cooperation. Shaw et al. (2007) said IM use influences positively on improving productivity in the workplace by a reduction in voice mail and phone tag, and improvement in checking if colleagues are available online to communicate (Shaw et al., 2007). C. M. Graham and Jones's research (2019) supports the same position in the use of social network messaging apps for collaborative work. They said social network messaging apps could be helpful to share a sense of common ground between team members and to engage students better and improve learning in project teamwork.

However, there is also a concern about some distractions caused by IM as well. When asked whom they contact most often at work, $40 \%$ of IM users said that they use IM to communicate with coworkers and 33\% with friends and family. Another pitfall is that IM may increase gossip/rumors, so it may create a stressful situation at a workplace (Pew Research Centre, 2004).

Although IM is based on text messages, the user may check if a counterpart on a private list is online and available for live chatting or not. This feature enables real-time telecommunication, and it makes IM distinct from other text messaging services. As a common feature of CMC, IM also allows users enough time to reflect on the situations and to respond accordingly.

This feature specifically appeals to the users who don't like any threatening/embarrassing situations caused by face-to-face communication. It may lead to better exploration, excitement, confidence, more engagement, and responsibility, as well as a better understanding of situations and discovery of new insight (Young, 2003).

This study is one of the few attempts to investigate student acceptance of CMC technology in business planning. In response to the call for a holistic model explaining CMC technology, we have tested a conceptual model of information product quality to explain student acceptance of CMC from an informational, physical, and service theoretical frame. This effort was successful in generating several new insights about the perceived quality nature as determinants of CMC use. Reliability of measurement items of each motivation and concern was ensured. Cronbach's alpha for each motivation and concern is $>.70$, and all of the values are statistically significant $(p<.05)$. Factor analysis using SPSS was conducted with maximum likelihood extraction with iterations to test and validate the conceptually developed three quality components. A factorial analysis has allowed the model to be rearranged. The three factors are labeled: (1) Physical, (2) Information, and (3) Service. This three-factor result supports Nam's Information Product Quality Model (2009, 2014). Different sets of quality attributes may be considered important in a different social, cultural, and situational context. Similar attempts integrating three components of quality for a holistic view of quality have been made by other researchers. Xu et al. (2013) proposed the 3Q model in the e-service context by including the Service Quality and its relationships with System Quality and Information Quality in website adoption. In their 3Q model, information quality includes four attributes (completeness, accuracy, format, currency), System Quality includes four attributes (reliability, flexibility, Accessibility, \& Timeliness). Service Quality includes five attributes (Tangibles, Responsiveness, Empathy, Service Reliability, and Assurance). Kanwal and Rehman (2016) also paid attention to the three components of quality when they studied the user's satisfaction towards e-learning systems in Pakistan. They found that information quality, service quality, and system quality were the positive and significant indicators for user satisfaction. Wang and Lin (2017) also focused on these three components of quality when they investigated the effect of perceived quality on their trust in location-based services. Location-based services are a type of app that detects the location where the device is located and can provide information such as routes, attractions, and traffic conditions. As there is a privacy concern in the use of 
location-based services, they examined how the perceived quality of the app affects user's trust in the app. They found that the information quality, system quality, and service quality of the app were positively related to the perceived trust.

In our research, among the three factors, (1) Physical factor appeared to be the most important because it explained the largest portion $(39.28 \%$ ) of the total variance (Figure 2).

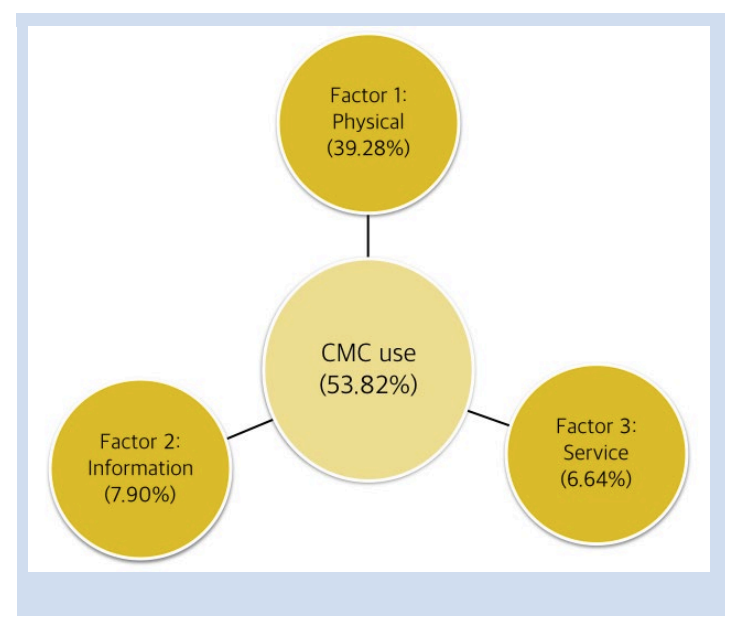

Figure 2: Rotated Loading Results

Physical factors were indicated by the attributes "Speed," "Accessibility," "Timeliness," "Convenience," "Interactivity," and "Assurance." "Convenience" is most highly correlated with a rotated loading score of .854 (Figure 3).

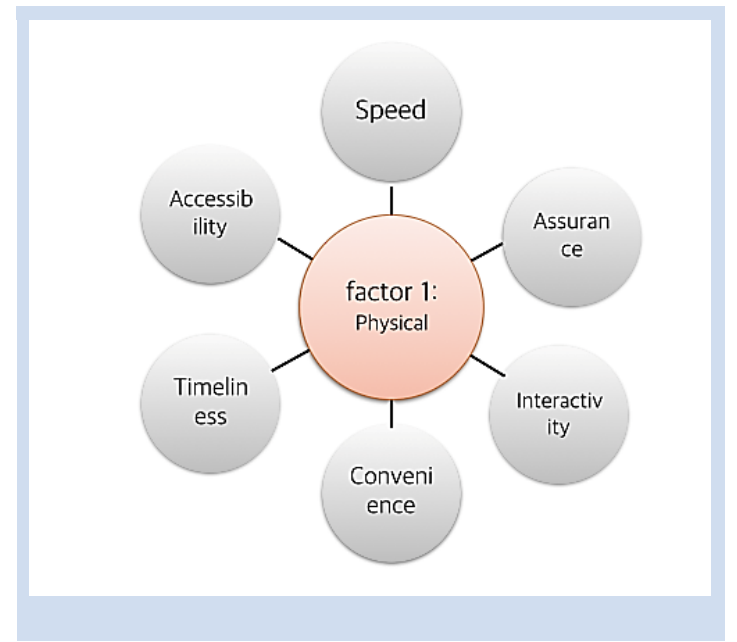

Figure 3: Factor 1 Physical

Information factors explained $7.9 \%$ of the total variance. Information factor was indicated by the attributes "Conciseness", "Comprehensiveness", "Clarity", "Accuracy", "Consistency". "Conciseness" is correlated with the highest rotated score .724 (Figure 4). 


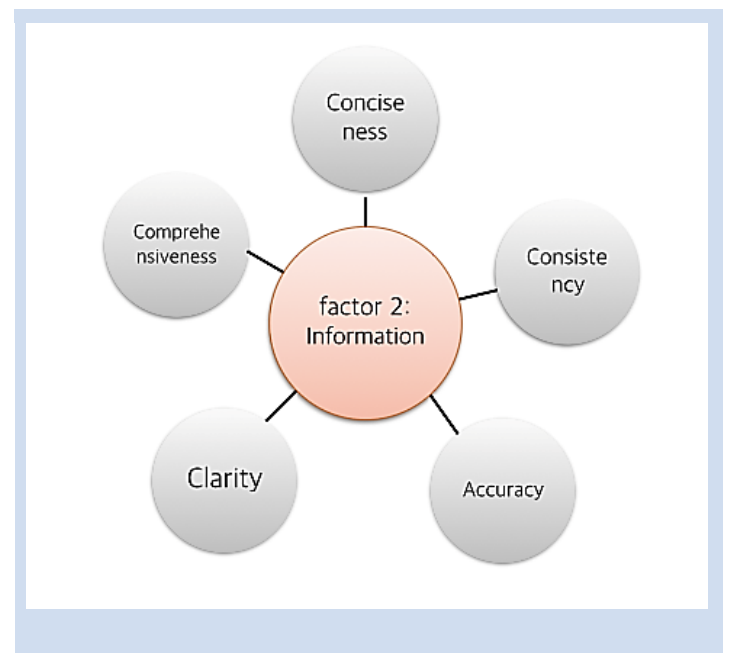

Figure 4: Factor 2 Information

The service factor explained $6.64 \%$ of the total variance. Service factor was indicated by the attributes "Reliability," "Responsiveness," "Assurance," and "Tangibility." "Reliability" is correlated with the highest rotated score, .759 (Figure 5).

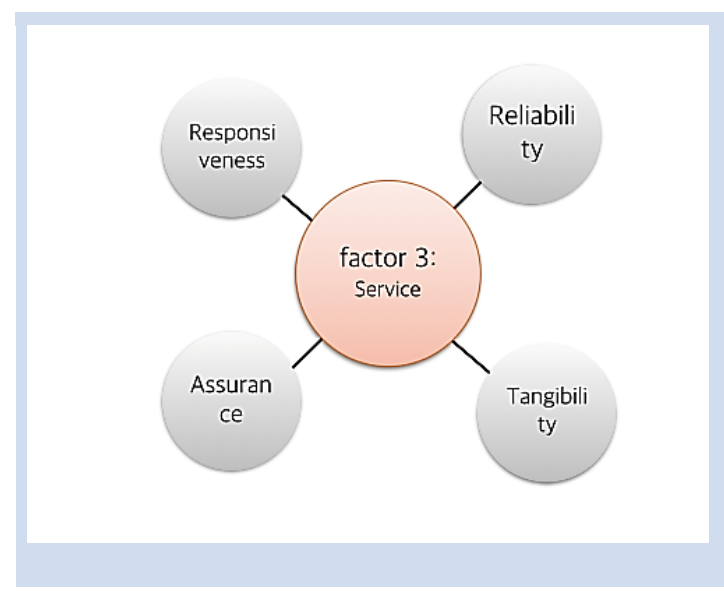

Figure 5: Factor 3 Service

It is remarkable that the physical component of quality appeared the most important in CMC use for business planning collaboration. Little is known regarding the importance of physical components of quality in the use of CMC. As a user nowadays carries his/her own portable devices to access various CMC technologies, convenience seems a very important attribute measuring the CMC perceived quality. Specifically, in the use of IM for real-time communication, 'Convenience' was pointed out as the most important attribute. Major concerns of quality research still remained only in the Information component of quality.

Information quality has been pointed out as an indicator of online e-commerce customer satisfaction (Lin, 2007). Muhammad et al., tested if information quality affects online customer's commitment, and they found that information quality positively influences e-satisfaction and e-trust (Muhammad et al., 2014). Ou and Davison (2016) examined how communication quality and mutual trust contribute to the development of interpersonal relationships from working professionals in China. They found that synchronicity mediates the direct relationship between IM use and interpersonal relationship. They also found that communication quality mediates the direct relationship between IM use and trust. This finding suggests that even with the IM physically installed, employees' mutual trust cannot be achieved without quality communication. In their study, communication quality refers to 
the employee's perception of the quality of communication in terms of being timely, adequate, accurate, complete, interactive, and effective.

\section{Theoretical and Practical Contributions}

First, given the theoretical importance of integrating information, physical, and service components of information products (Nam, 2014; Nam, 2009), three factors were identified as the most important component of $\mathrm{CMC}$ quality in business planning. By presenting a theory of quality on the use of $\mathrm{CMC}$ in business planning, our work contributes to research in multiple ways. First, our theory contributes to the literature discovering important quality factors in CMC use, specifically in business planning. Prior research has largely focused only on informational components of quality. In this study, we emphasize the importance of three components, Physical, Information, and Service components of quality, in explaining CMC use, specifically in business planning.

Second, the physical component was identified as the most important component in the use of CMC in business planning. Even though there are several attempts to integrate informational, physical, and service components of quality explaining media, major research domains remain in the focus of the information component only. This research highlights the importance of physical components in the use of $\mathrm{CMC}$ as 'convenience' is regarded as the key attribute in measuring users' perceived quality. Using mobile devices, people can access CMC technology in real-time. This finding points out the importance of physical quality components in the measuring quality of CMC.

Third, quality is recognized as an explanatory variable of the use of CMC in business planning. In theories based on the TAM model, the use of mandatory, work-related information systems has mostly been the focus. Therefore, the explanation has been limited in some senses. Although various quality attributes have been identified before, little is known about which quality factor is perceived as important in the use of CMC in business planning. This study shed light on quality research, specifically in the use of CMC. As the focus of our study is on user-perceived quality, we offer a user-level understanding of the use of CMC about what quality factors drive the choice of a specific CMC for collaborative works.

With the growing role of $\mathrm{CMC}$ technologies nowadays, our study has practical implications for enhancing CMC technology performance. This study informs the importance of 'Convenience' in $\mathrm{CMC}$ design to yield a higher value proposition to $\mathrm{CMC}$ users. The prominence of the Convenience attribute has important implications for app developers, particularly those who have tended to ignore physical factors. The significant quality attributes related to CMC use will provide insight to app developers about which features they should consider in designing CMC. Our proposed quality model can be prescriptive to managers and designers on how to design a new CMC specifically for collaborative work. Articulation of these factors would help identify potential problems that may significantly promote or hinder use when web designers, managers, and users evaluate the quality of a CMC tool.

\section{LIMITATIONS AND FUTURE RESEARCH}

The threat to external validity comes from the fact that it tested a limited number of subjects, tasks, and specific contextual situations. The student subjects may not represent a general population. Students' use of CMC technologies is tested to test CMC use in a work setting. Even if their use of $\mathrm{CMC}$ is for business planning as coursework, their student status may affect the choice or use of CMC. For another population, different motivational factors may appear significant. For example, the senior group of people may face more technical/physical challenges in the use of CMC (ex. optical problems) compared to the student population (Chou et al., 2013). Their perceived quality of $\mathrm{CMC}$ may be different. Future research will shed more light on the generality of these findings. Future studies should be extended to other populations and contextual situations in the use of CMC. 


\section{CONCLUSION}

The purpose of this study was to examine the user's perceived quality of CMC technology in business planning. The three components (Physical, Information, and Service) were found as significant quality factors. These findings contribute to a better understanding of the use of CMC in business planning. Future studies should be extended to other populations and contextual situations in the use of CMC.

\section{REFERENCES}

Alter, S. (2002). Information system: The foundation of e-business (4th ed.). Prentice-Hall.

Anderson, J. C., \& Gerbing, D. W. (1988). Structural equation modeling in practice: A review and recommended two-step approach. Psychological Bulletin, 103(3), 411-423. https://doi.org/10.1037/0033-2909.103.3.411

Babbie, E. (1990). Survey research methods (2nd ed.). Cengage Learning.

Baltes, B. B., Dickson, M. W., Sherman, M. P, Buer, C. C, \& LaGanke, J. S. (2002). Computer-mediated communication and group decision making: A meta-analysis. Organizational Behavior and Human Decision Processes, 87(1), 156-179. https://doi.org/10.1006/obhd.2001.2961

Beal, V. (2019, September 05). Instant messaging. Webopedia. https://www.webopedia.com/TERM/I/instant messaging.html

Chua, Y. P. (2014). Ujian Regresi, Analisis Faktor, dan Analisis SEM [Regression Test, Factor Analysis and SEM Analysis] (5th ed.). McGraw Hill Education.

Chou, W. H., Lai, Y., \& Liu, K. (2013). User requirements of social media for the elderly: A case study in Taiwan. Behavior and Information Technology, 32(9), 920-937. https://doi.org/10.1080/0144929X.2012.681068

Crosby, P. (1980). Quality is Free. McGraw-Hill.

Daft, R. L., \& Lengel, R. H. (1986). Organizational information requirements, media richness, and structural design. Management Science, 32(5), 554-571. https://doi.org/10.1287/mnsc.32.5.554

Deming, W. E. (1986). Out of crisis. Massachusetts Institute of Technology.

Dunn, S. C., Seaker, R. F., \& Waller, M. A. (1994). Latent variables in business logistics research: Scale development and validation. Journal of Business Logistics, 15(2), 145-172. https://trid.trb.org/view/552217

Ellison, N. B., Steinfield, C., \& Lampe, C. (2007). The benefits of Facebook "Friends:" Social capital and college students' use of online social network sites. Journal of Computer-Mediated Communication, 12(4), 1143 1168. https://doi.org/10.1111/j.1083-6101.2007.00367.x

Eppler, M. (2003). Managing information quality. Springer-Verlag. https://doi.org/10.1007/978-3-540-24782-1

Fulk, J., Schmitz, J., \& Steinfield, C. W. (1990). A social influence model of technology use. In J. Fulk, \& C. Steinfield (Eds.), Organizations and communications technology (pp. 117-140). Sage Publications. https://doi.org/10.4135/9781483325385.n6

Global Workplace Analytics. (2018, July). Telecommuting trend data. http://globalworkplaceanalytics.com/telecommuting-statistics

Gorman, G., Hanlon, D., \& King, W. (1997). Some research perspectives on entrepreneurship education, enterprise education and education for small business management: A ten-year literature review. International Small Business Journal: Researching Entrepreneurship, 15(3), 56-77. https://doi.org/10.1177/0266242697153004

Graham, C. M., \& Jones, N. (2019). Impact of a social network messaging app on team cohesiveness and quality of completed team projects in an undergraduate team project. Journal of Educational Technology Systems, 47(4), 539-553. https://doi.org/10.1177/0047239518821937

Graham, R. (2014, June). Creating university-based entrepreneurial ecosystems: Evidence from emerging world leaders. MIT Skoltech Initiative. https://www.rhgraham.org/resources/MIT:Skoltech-entrepreneurial-ecosystems-report-2014-.pdf 
Hair, J. F., Black, W. C., \& Babin, B. J. (2010). Multivariate data analysis: A global perspective. Pearson Prentice Hall.

Hills, G. (1988). Variations in university entrepreneurship education: An empirical study of an evolving field. Journal of Business Venturing, 3(2), 109-122. https://doi.org/10.1016/0883-9026(88)90021-3

Honig, B. (2004). Entrepreneurship education: Toward a model of contingency-based business planning. Academy of Management Learning \& Education, 3(3), 258-273. https://doi.org/10.5465/amle.2004.14242112

Kanwal, F., \& Rehman, M. (2016). Measuring information, system, and service qualities evaluation of e-learning systems in Pakistan. Pakistan Journal of Science, 68(3), 302-307. https://www.proquest.com/openview/2188f39ada2765ce8f701900549cbf41/1

The Korea Herald. (2017, January 01). KaKaoTalk is stuck in Korea. http://www.koreaherald.com/view.php?ud $=20161230000458$

Ku, Y. C., Chu, T. H., \& Tseng, C. H. (2013). Gratifications for using CMC technologies: A comparison among SNS, IM, and email. Computers in Human Behavior, 29(1), 226-234. https://doi.org/10.1016/i.chb.2012.08.009

Lin, H. F. (2007). The impact of website quality dimensions on customer satisfaction in the B2C e-commerce context. Total Quality Management and Business Excellence, 18(4), 363-378. https://doi.org/10.1080/14783360701231302

Muhammad, Z., Yi, F., Naz, A. S., \& Fahad, K. M. (2014). An empirical study on exploring relationship among information quality, E-satisfaction, E-trust and young generation's commitment to Chinese online retailing. Journal of Competitiveness, 6(4), 3-18. https://www.cjournal.cz/files/177.pdf

McQuail, D. (2005). McQuail's mass communication theory (5th ed.). Sage Publications.

Nam, J. (2009, July). Web portal quality. In Proceedings of the IEEE/INFORMS International Conference on Service Operations, Logistics and Informatics (pp. 163-168). Chicago, USA: IEEE. https://doi.org/10.1109/SOLI.2009.5203923

Nam, J. (2014). Understanding the motivation to use web portals. Computers in Human Behavior, 36, 263-273. https://doi.org/10.1016/j.chb.2014.03.074

Ou, C. X. J., \& Davison, R. M. (2016). Shaping guanxi networks at work through instant messaging. Journal of the Association for Information Science and Technology, 67(5), 1153-1168. https://doi.org/10.1002/asi.23447

Peterman, N. E., \& Kennedy, J. (2003). Enterprise education: Influencing students' perceptions of entrepreneurship. Entrepreneurship Theory and Practice, 28(2), 129-144. https://doi.org/10.1046/j.1540$\underline{6520.2003 .00035 . x}$

Pew Research Centre. (2004, September 01). How Americans use instant messaging. https://www.pewinternet.org/2004/09/01/how-americans-use-instant-messaging/

Shapiro, C., \& Varian, H. (Nov/Dec, 1998). Versioning: The smart way to sell information. Harvard Business Review, 76, 107-115. https://hbr.org/1998/11/versioning-the-smart-way-to-sell-information

Shaw, B., Scheufele, D. A., \& Catalano, S. (2007). The role of presence awareness in organizational communication: An exploratory field experiment. Behavior \& Information Technology, 26(5), 377-384. https://doi.org/10.1080/01449290500484450

Scheibe, K. P., \& Gupta, M. (2017). The effect of socializing via computer-mediated communication on the relationship between organizational culture and organizational creativity. Communications of the Association for Information Systems, 40(1), 13. https://doi.org/10.17705/1CAIS.04013

Sirait, E. R. E., \& Zellatifanny, C. M. (2020, October). An empirical study: Computer-mediated communication and collaboration among government employees during flexible working arrangements. In Proceedings of the International Conference on Information Technology Systems and Innovation (ICITSI) (pp. 95-100). Bandung, Indonesia: IEEE. https://doi.org/10.1109/ICITSI50517.2020.9264968

Tabachnick, B. G., \& Fidell, L. S. (2007). Using multivariate statistics (5th ed.). Pearson Education Inc. 
Tate, T. D., Lartey, F. M., \& Randall, P. M. (2019). Relationship between computer-mediated communication and employee engagement among telecommuting knowledge workers. Journal of Human Resource and Sustainability Studies, 7(2), 328-347. https://doi.org/10.4236/ihrss.2019.72021

Wang, E. S. T., \& Lin, R. L. (2017). Perceived quality factors of location-based apps on trust and continuous usage intention. Behavior \& Information Technology, 36(1), 2-10. https://doi.org/10.1080/0144929X.2016.1143033

Xu, J., Benbasat, I., \& Cenfetelli, R. T. (2013). Integrating service quality with system and information quality: An empirical test in the e-service context. MIS Quarterly, 37(3), 777-794. https://doi.org/10.25300/MISQ/2013/37.3.05

Young, S. S. C. (2003). Integrating ICT into second language education in a vocational high school. Journal of Computer Assisted Learning, 19(4), 447-461. https://doi.org/10.1046/j.0266-4909.2003.00049.x

\section{AUTHOR}

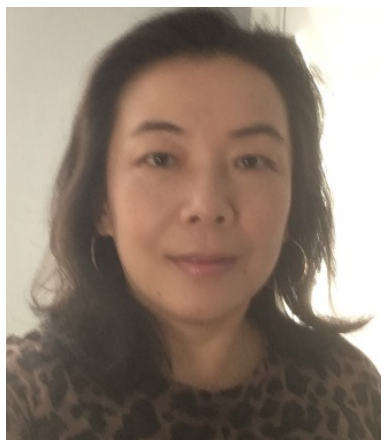

Junghyun Nam is Limited Term Faculty, University of North Georgia. Her research interest is in Computer-mediated Technology use, \& Motivation, and Quality of various Information Products. 